\title{
GREEN INFRASTRUCTURE BENEFITS TO VALUE AND ENHANCE THE BUILT ENVIRONMENT: THE CASE OF ADDIS ABABA, ETHIOPIA
}

\author{
SAMUEL MOSISSA $^{1}$, ZHONGWEI SHEN $^{1}$, GASHAW ASEFA ${ }^{2} \&$ AMANUEL WOLDESEMBET $^{3}$ \\ ${ }^{1}$ Southwest Jiaotong University, China \\ ${ }^{2}$ ITDP Africa, Kenya \\ ${ }^{3}$ EIABC, Ethiopia
}

\begin{abstract}
Green infrastructure (GI), as a term, is subject to a wide range of definitions and functions. As a core identity, it holds connectivity and multifunctionality. GI supports the ecological, social, and economic roles of urban areas by linking different infrastructural developments with nature. Thus, the first objective of this article is to explore green infrastructure definitions, benefits, and assets. And then to assign a category of multifunctionality. What green infrastructure benefits do the individual assets deliver? The second is to evaluate the green infrastructure assets benefits in the case of Addis Ababa and determine the estimated GI value difference. The estimated GI value difference is the percentage gap between the current benefit of GI assets and the possible benefits GI assets could give. It is determined through expert opinion methodology; experts selected from academic department lists, who, one way or another, study about the city GI issues. The scope of the study mainly focuses on the central and southeast parts of the city. Besides the expert opinions, in order to assess the current situations and the strategies that are currently employed by Addis Ababa city government, the paper uses site surveys, maps and secondary data from the city administration. The result of the study shows that, even though the city of Addis Ababa is losing green coverage rapidly, the new projects in hand are encouraging. The GI value difference result indicates a considerable gap between the possible benefits GI assets could give and the current benefits they are offering. Thus, the paper suggests Addis Ababa municipality needs to integrate new green infrastructure strategies and strengthen the employed GI strategies to increase the category of multifunctionality.

Keywords: green infrastructure (GI), multifunctionality, GI assets, GI benefits, GI value.
\end{abstract}

\section{INTRODUCTION}

Green infrastructure (GI) comes as a development strategy in linking nature with development; the main thought of green infrastructure is to link human and nature. Naumann et al. [1] describe green infrastructure as the harmonious delivery of services for both humans and ecology. The term, however, used to show different benefits depending on the place GI used. In general, definitions of GI revolve around connectivity and multifunctionality, which are the basic elements of green infrastructure. Though there is no commonly accepted, single definition of green infrastructure, there are shared multifunctional area of use, for example [1]-[3] see GI from the area of network and connecting community use [4], [5] from air quality improvement use [6], [7] from better health, and so on.

The listed area of use shares common objectives, to provide a multifunctional infrastructure that is connected. Connecting a network of spaces and a wider range of functions demonstrates the benefits that GI can deliver [8]. Refers to green infrastructure holistically to the connectivity and type of assets. Which together deliver multiple benefits [9]. Multifunctionality combines economic, sociocultural, and ecological advantages. That shows that green infrastructure provides a diverse and wide range of benefits, furthermore, with opportunities for social, economic, and environmental benefits [8]. 
That is why GI needs the attention of cities like Addis Ababa, which are on the verge of development. The increasingly fragmented nature of Addis Ababa city as a result of landuse intensification, demands the integration of green infrastructure into different sectors of development. This paper outlines green infrastructure assets and benefits. The role of GI assets play is called GI functions, and the assets and functions have the potential to provide a wide range of benefits [9]. With GI assets and GI benefits, the paper understands and evaluates the case of Addis Ababa. And inform the multiple benefits green infrastructure delivers to communities.

\section{DOES THE CITY OF ADDIS ABABA NEED GI STRATEGIES?}

Addis Ababa - like many other cities - faces the same pressures of a scarcity of resources, climate change, pollution, environmental degradation, and dangers to human health. A lack of reaction to these issues will have direct results. Addis Ababa, the home of the African Union and other international organizations, is located within the Central plateau of Ethiopia. In many terms, the growth of a city is defined by its infrastructure. Disturbingly though, the city is losing its green areas.

According to Addis Ababa city Government plan commission [10], the city is losing it is green coverage at a devastating speed. In 1986 from the total city area, 32,083 ha was covered by green; in 2003, it becomes 21,538 ha, and in 2016 it reduced to 16,265 ha, almost lost half of the green parts that were in 1986. According to the city government plan commission projection, if this continues like that by the year 2040, the green coverage becomes 2,405 ha (Fig. 1). Yes, the city needs to wake up and restore its green.

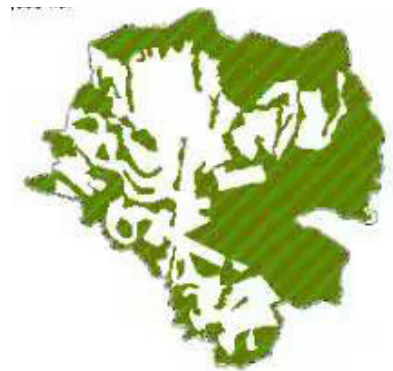

(a)

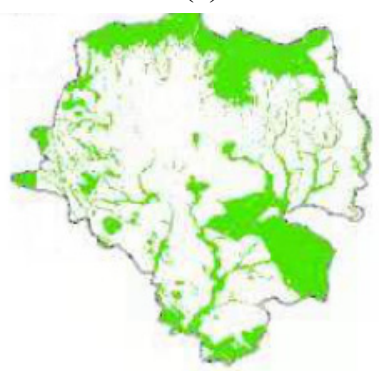

(c)

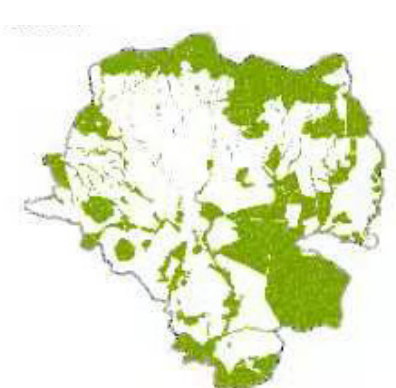

(b)

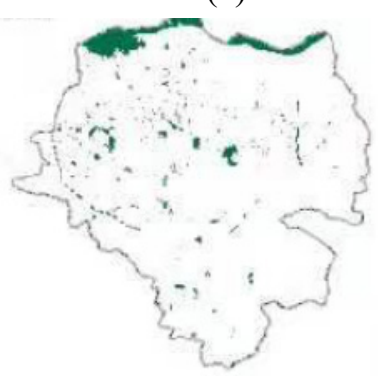

(d)

Figure 1: Green coverage map. (a) In 1986; (b) Change from 1986 to 2003; (c) Change from 2003 to 2016; and (d) Expected green cover in 2032. (Source: Addis Ababa City Plan Commission 2019.) 
The city streets regularly are covered by with stormwater. The topography of Addis Ababa increase the flooding, there is an elevation change from $3,000 \mathrm{~m}$ in the north to $2,100 \mathrm{~m}$ in the southern part of the city.it has a regular impact on the city streets, when it rains the streets become rivers of storm-water runoff (Fig. 2).
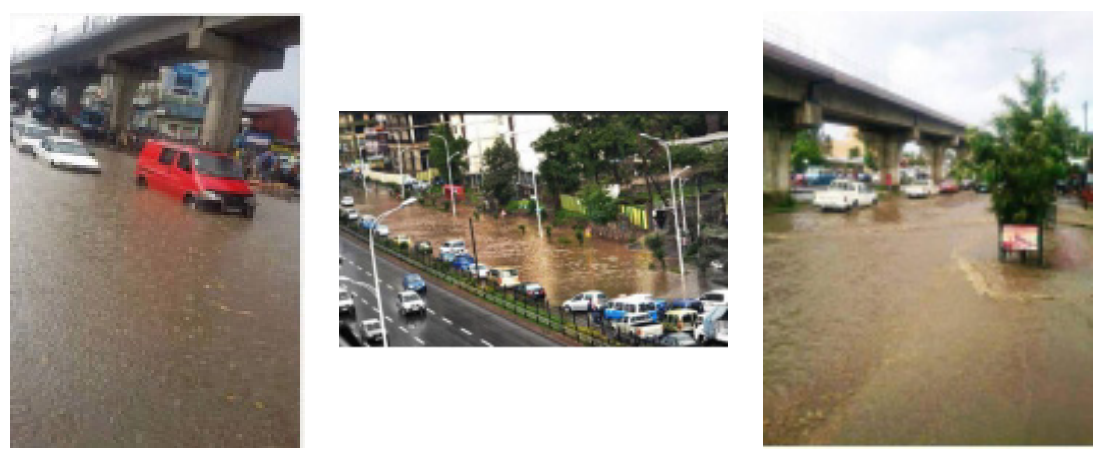

Figure 2: Storm water run-off in Addis Ababa 2020.

Climate change, flash floods, heatwaves, and drought, are significant environmental problems related to the city (Jalayer et al. [11]). Yes, the city of Addis Ababa needs to pay attention to green infrastructure as it is doing for the gray infrastructure.

\subsection{Addis Ababa city encouraging strategies}

Recently the city of Addis Ababa is making attempts to improve the city's condition.

- The city is making attempts to make streets green and comfortable for pedestrians. The city is engaged in creating $600 \mathrm{~km}$ of walkways, $200 \mathrm{~km}$ of cycling paths and established car free days (ITDP [12]).

- Late 2019 the city turned a late 19th century palace in it is capital Addis Ababa into a park/zoo/museum and major tourist destination

- Rivers in Addis Ababa are a main part of the city, which it seems to be neglected for decades and use them as a disposal site and polluted. In 2019, a project introduced to develop the riversides cleaner and green habitable space for residents and visitors. Beautifying Sheger Project aims to make rivers a model of green infrastructure.

- Indian world breaking tree planting and New York city to plant and care for one million new trees across the city show the impact and value given for trees. Surprisingly Addis Ababa and other Ethiopian cities planted on July 30, 2019, About 353 million trees in a single day (CNN [13]) and the government planned to make it as a culture in the future too.

- Rehabilitation of $3 \mathrm{~km}^{2}$ between the suburbs of Entoto and Akaki.

Dedication of the government towards GI is encouraging. Given the significance, further study is needed to show the value of GI and the degree of multifunctionality.

\section{METHODOLOGY}

Understanding the benefits and assets of green infrastructure is a critical element of this study. The research methodology has two main parts. The first part is the paper search main 
concepts, assets, and benefits related to Green infrastructure. Demonstrates findings of reviews on the summaries of benefits that GI can deliver. With that, A checklist prepared with the list of GI benefits and assets, that enables experts to identify linkages between 25 GI benefits with 19 GI assets within Addis Ababa city context. The second method is developed to determine GI value relative difference and to evaluate the case study degree of multifunctionality. GI value relative difference is the percentage gap between the current benefit of GI assets in the city and the possible benefits the GI assets could give if enhanced. The degree of multifunctionality is the benefits achieved by the current GI assets in the study, through repetitive site investigation, Academic expert's inputs, map, and data collected from government offices.

Methods used by City of Bradford Metropolitan District Council [14] and Elliott et al. [15] are adopted. For Green infrastructure assets, benefits, and their category of multifunctionality method, [14] and expert opinion [15] are adopted. Academic experts identified, from available information of department lists and networking with experts, who one way or another study about the city green issues. Ten experts were available to cooperate. We set the task with a checklist prepared with the list of GI benefits and criteria for measuring the GI assets. Their evaluation and opinion were assembled and send back to the experts for comment and discussion.

To determine what green infrastructure benefits do the individual assets deliver? The assets are assigned to a category of multifunctionality [14]:

Assets with $>11$ GI benefits have very high levels of multifunctionality.

Assets with 9-10 GI benefits have high levels of multifunctionality.

Assets with 7-8 GI benefits have medium levels of multifunctionality.

Assets with 5-6 GI benefits have a low level of multifunctionality.

Assets with $<4$ GI benefits have a very low level of multifunctionality.

After identifying the level of multifunctionality with the expert's opinions. The value difference is calculated. Which is the difference between each assets, possible GI benefits (PGIB) with each asset current GI benefits (CGIB). To determine GI value relative percentage difference, we used a relative percentage differences calculator. Which Convert the GI value difference to a percentage. The higher the relative Percentage difference is, the higher the assets need attention.

$$
G I \text { value relative percentage difference }=\left[\frac{[P G I B-C G I B]}{(P G I B)}\right] \times 100 \text {. }
$$

\subsection{Methodology outline}

Analysis of results from site investigation and academic experts opinion reveals that GI value difference is highest compared to the possible potential benefits GI could give, and lowest for the category of multifunctionality (Fig. 3).

\section{GREEN INFRASTRUCTURE BENEFITS}

Green infrastructure provides many services that enable landscapes to deliver social, economic, and environmental benefits simultaneously. And then looks at how those benefits can be multiplied by being connected to a broader network of spaces. cities have explored GI within their municipal infrastructure programs. 


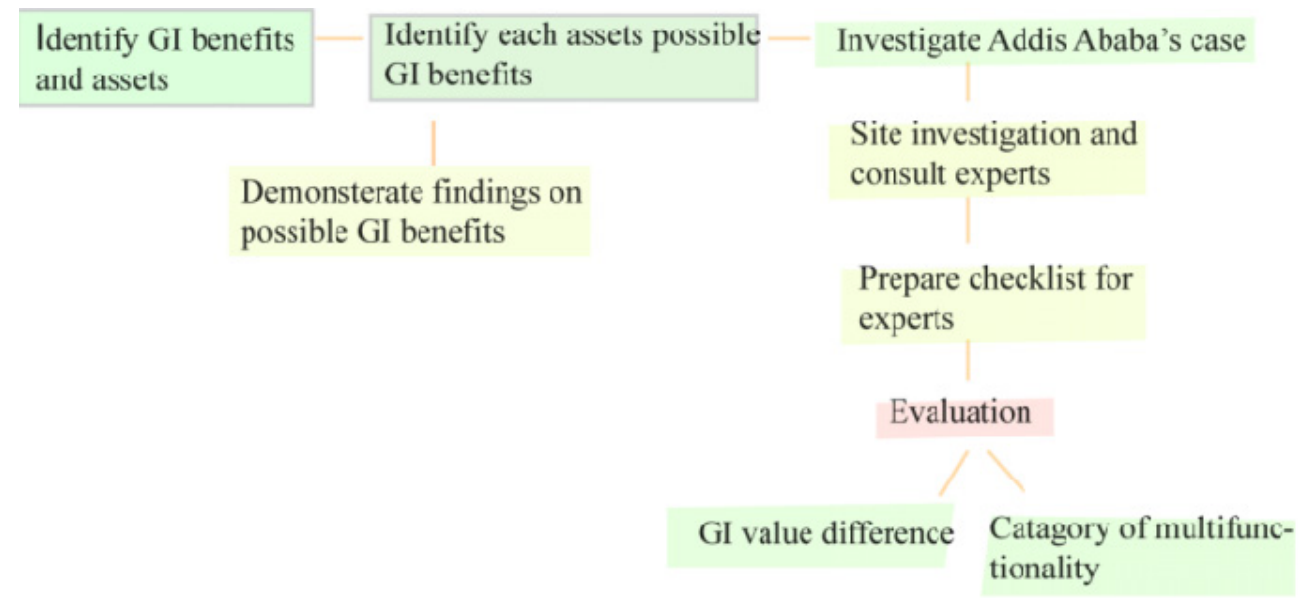

Figure 3: Method outline.

\subsection{Potential green infrastructure assets}

This section demonstrates the findings of reviews on the summaries of benefits that GI can deliver.

A. Provide safe and attractive links between community facilities: According to Benedict and McMahon [2] in their book GI linking landscapes and communities, explains how green infrastructure links communities and creates safe places. It is not just land that is going to develop; instead, these open spaces connect communities and outdoor heritages. The biodiversity connection is secured study by Burley [16] indicates a GI impact on violent crime reduction, making communities safe.

B. Social interaction: Green infrastructure assets increase the social interaction between society. A study by Rasidia et al. [17] and Tzoulas et al. [18] show that green space has an impact on the social interaction of residents. Furthermore, it increases social cohesion [19].

C. Improving physical activity and health: there is a relationship between physical activity and good health. Studies show the bond between green spaces and high level of physical activities [8]. Well-developed green infrastructure support in creating a healthy society, also there exists a positive relationship between green spaces and physical well beingness. Tzoulas et al. [18], Lennon et al. [20] and Mekala et al. [21] discuss that public parks, trees, and green routes can provide resources for healthy lifestyles for residents.

D. Mental health: the natural environment, which green infrastructure relies on benefits, mental health development. Ulrich et al. [6], Tzoulas et al. [18] and Mekala et al. [21] report natural environment helps a person to recover from stress aspects of emotional, attentional, and physiological issues. Benedict and McMahon [2] report the physical and mental benefits GI provides by living near nature.

E. Attractive places for living: Opportunities GI provides for recreation, walking, biking, fishing, makes a place attractive place to live. Benedict and McMahon [2] report not only GI becomes an attractive place to live but also attracts others to visit. 
F. Attractive places for working/studying: Green infrastructure improves the quality of people who are living and working in it [8]. Institutional green spaces and Amenity green spaces, green parking, and green buildings are spaces highly associated with attractive places for working or studying [22].

G. Attractive places and routes for recreation: Green infrastructure provides attractive places for recreation [2], [3]. Places in the scope of green infrastructure are attractive and inviting for recreation.

H. Attractive places for increasing land/property values and demand: Green infrastructure can help to achieve housing demands for communities that want more housing [2]. Near by the development of green infrastructure amenities benefits the property values [8], [21].

I. Reduce urban run-off, reduce flood risk, mudslide, and other natural disasters: To move stormwater away from the built environment, Grey infrastructures used largely, while GI reduces stormwater and treat it. To reduce flood risk and other natural disasters through GI has been mentioned in a lot of GI books and papers [2], [8], [23][27].

J. Urban cooling: In urban areas, green infrastructure has a role in controlling the warm temperature [8]. From GI assets, trees play a significant role in the urban environment, urban green infrastructure help achieve temperature reductions. The temperature reduction makes urban areas cool [4]. Dixon and Wolf [25] and Gill et al. [26] suggested that increasing green infrastructure areas could result in urban cooling.

K. Improve air quality: GI has a diverse use, such as pollution reduction [4], [21], [26]. Urban forest, woodland, and street trees are among the green infrastructure asset that improves air quality. Trees influence the formation of ozone, removing air pollutants, and the direct production of oxygen [8], [25].

L. Provides an Attractive setting for townscape / cultural heritage assets: the physical attractiveness of cities and comfort is attained through GI. According to Forest Research [8] visual appearance and increasing environmental quality and aesthetics are some of the benefits of GI.

M. Provide a local environmental resource for education and skills development: Green infrastructure provides environmental resources for education, both indoor and outdoor learning that promote place-based learning [28]. The educational services GI assets offer to citizens are science and education [15].

N. Provide attractive places for tourism: GI assets are places for the community to enjoy and attract tourists [21]. GI assets like open spaces, hiking trails, green spaces of public institutions, and lakesides, are a catalyst for tourism development [22].

O. Carbon sequestration: Is the process trees, grasses, and other plants extract carbon from the air. Some of the assets that are related to carbon sequestration are urban forest, street trees, woodland and park trees balance carbon, including direct carbon sequestration [21], [23], [26].

P. Provide habitat/habitat for fish, wildlife species: Green infrastructure is the way to protect the earth's biodiversity; it connects and ensure habitats existence [2]. GI has a diverse use, such as habitat biodiversity [4], [21].

Q. Provide attractive places for securing inward investment: emphasizing GI increases people's enjoyment of an area and attract business. As a result of green spaces in the UK, there are instances of investment and economic growth [8].

R. Provide wildlife corridors: A robust network of green infrastructure provides wildlife corridors. Greenways play a significant role in attaining connectivity between GI assets. The greenway protects a river corridor and protects corridors for wildlife [3]. 
S. Provide local food and energy production: GI assets provide food production, food supply and energy source for the community. Community gardens and urban agriculture provide food production through fruit and vegetation [15].

T. Economic benefits: Green infrastructure plays a crucial part in benefiting a city's economy. It can be quantified through inward investment, and job creation, land and property values, local economic regeneration [8]. Green infrastructure assets like urban forests have the potential of developing a country's economy [29].

U. Reduce traffic accidents: there is a way landscape design along the road help to reduce traffic accidents. Through reducing the stress of drivers and not only that designed GI alters driver comfort by giving relief from the sun and wind but also has an impact on traffic accident reduction [25].

V. Buffered against drought: An integrate GI is home and source of food for different habitats. Langurs (a type of monkey) in Jodhpur city were buffered against drought because of the availability of urban green habitat and food (Waite et al. 2007 in Singh et al. [30]).

W. Sound pollution: Urban forests, greenway, street trees, green roofs are some of the GI assets that help to reduce noise, which is an environmental problem. Studies support the tree's capacity in noise reduction in the urban ecosystem. The relation of green spaces and noise by [31].

X. Watersheds /water resources: GI benefits to improve water quality in urban watersheds [2]. Green infrastructure improves runoff quality [27].

\subsection{Green infrastructure assets}

GI assets, also called GI types, range from country parks, lakes, and woodlands to urban interventions such as green roofs and street trees. They can be specific sites at the local level, or broader environmental features at the landscape scale within and between rural and urban areas such as wetlands, fields, and mountain ranges. Below is a list of assets gathered from the literature reviews.

\subsubsection{Check list for green infrastructure assets and benefits}

The selected list is determined from the papers reviewed. The checklist with the list of GI benefits and GI assets, guide experts to address the 19(1-19) assets with the 24(A-X) GI benefits. Using the tables and map, experts assess the case of Addis Ababa.

\subsubsection{Addis Ababa: assets and benefits}

Taking the average of the expert's opinion on the chosen sites, expert's opinion is summarized to determine the multifunctionality level and the GI value difference.

The checklist reminds experts what points to consider and how to evaluate; It ensured consistency and completeness in evaluating the selected assets in Addis Ababa.

\section{RESULT AND DISCUSSIONS}

To analyze the estimated value differences and categories of multifunctionality, We explored the 19 GI assets with a possible 24 GI benefits. Fig. 5 shows the results of the model based on the expert's view. From the considered GI assets in Addis Ababa. Using the measurement of the category of multifunctionality [4]. Eleven assets are low, and below the category of multifunctionality, four medium, and four have a high category of multifunctionality Fig. 6. Considering the possible benefits that can be gain from the 19 GI assets, the result indicates that attention is needed for most of the assets evaluated. 
Table 1: Identified green infrastructure assets.

\section{Green infrastructure assets}

1. Public spaces (parks and other open spaces) (PS) - outdoor nature, wildlife and leisure center. (Peacock park)

2. Civic space (significant foot-ways/ small square) (CS) a place where we interact with each other and with community. (Meskel square)

3. Street trees (ST) trees growing along the city street. (Churchil avenue)

4. Institutional green spaces/ churchyards, cemeteries, burial grounds, universities (IGS)green space in an institutional area. (Addis Ababa university)

5. Abandoned/derelict land(DL) Informal recreational areas with a potential of GI development. (Ayat sefer)

6. Green space along rail corridor(GSC)a green Oasis following a rail way. Green and vibrant corridor. (Urael to Mexico)

7. Roadside green space(RGS) Green space associated with road network. (Hilton hotel corridor)

8. Amenity green spaces(AGS) spaces associated with parking, buildings but with no public use. (Bole around Friendship)

9. Urban forest(UF) a forest/group of trees within a city. (Yeka protected forest)
11. Greenbelts(GB) a strip of land surrounding a community or a city. (Entoto protected green area)

12. Green roofs (GR) with partly or fully covered with soil and plants overlaying on the roof. (African union Sarbet)

13. Woodlands/community woodlands (CWL) concentration of trees in a smaller land area. (Jan meda)

14. Green walls $(\mathrm{GW})$ vertical gardens. (Hope university college)

15. Wetlands (WL) water is at or near the surface. (Adwa park)

16. Agricultural land, farms, ranches (AL) land used for production of foods. (Bole Olympia urban agriculture)

17. Ground water recharge areas (GWR) land surface from which water moves to ground water. (Around Bole Airport area)

18. Blue infrastructure/sustainable drainage system SuDS schemes (BI) infrastructure related to water. (Urael area)

19. Private gardens $(\mathrm{PG})$ private open space. (Hayahulet area)

10. Greenways $(\mathrm{GW})$ a strip or corridor opens spaces that connect people and places, used for recreational or environmental protection. (back of St.Estifanos church) 


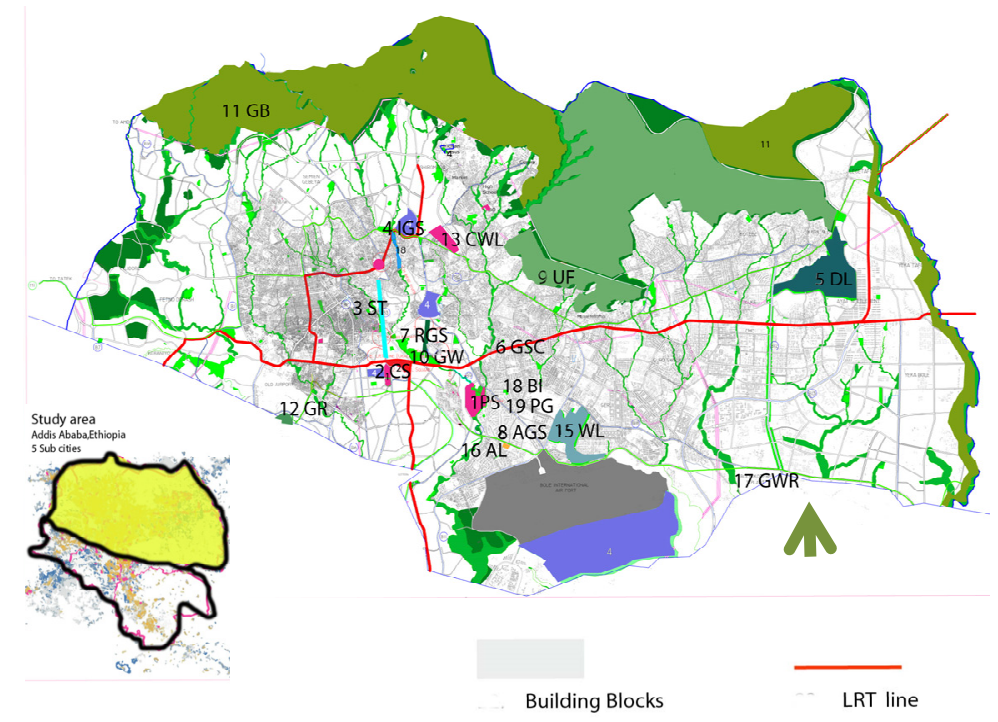

Figure 4: Location of the 19 green infrastructure assets in Table 1.

Table 2: Identified current GI benefits in Addis Ababa, through experts opinion.

\begin{tabular}{|l|l|l|}
\hline GI assets & $\begin{array}{l}\text { Identified current GI benefits } \\
\text { (CGIB) }\end{array}$ & Identified potential GI benefits (PGIB) \\
\hline 1.(PS) & B,D,F,G,J,L,N,P,T,W & A,B,C,D,E,F,G,H,I,J,K,L,N,P,S,T,U,W \\
\hline 2.(CS) & B,C,G,H,L,N,T & A,B,C,D,E,F,G,H,L,M,N,T \\
\hline 3.(ST) & F,I,J,L,O & A,E,F,G,H,I,J,K,L,O,P,R,S,W \\
\hline 4.(IGS) & D,F,G,I,J,K,L,O,P,R,W & A,B,C,D,E,F,G,I,J,K,L,M,O,P,R,S,W \\
\hline 5.(DL) & J,K,P & B,C,D,E,F,G,,H,I,J,K,L,M,O,P,Q,R,S \\
\hline 6.(GSC) & M & I,J,K,L,P,Q,R,W \\
\hline 7.(RGS) & A,H,L,U,W & A,E,F,G,H,I,J,K,L,O,P,Q,R,W \\
\hline 8.(AGS) & A,F,H,P,Q & E,F,H,I,J,K,O,P,Q,R,S,W \\
\hline 9.(UF) & C,D,G,H,I,J,K,L,O,P,R,S,T,V, & $\begin{array}{l}\text { A,B,C,D,F,G,I,J,K,L,M,N,O,P,Q,R,S,T,V } \\
\text { W,X }\end{array}$ \\
\hline 10.(GS) & W,X & $\begin{array}{l}\text { A,B,C,D,E,F,G,H,I,J,K,L,M,N,O,P,Q,R,S } \\
\text { S,U,W }\end{array}$ \\
\hline 11.(GB) & D,J,K,L,N,O,P,S & C,D,G,I,J,K,L,O,P,R,S,V,W \\
\hline 12.(GR) & F,L,M & E,F,G,I,J,K,L,M,O,P,S,T \\
\hline 13.(CWL) & D,I,J,K,L,O,P,S & B,C,D,E,G,I,J,K,L,M,O,P,Q,S,T,W \\
\hline 14.(GW) & F,I,J,L,M,T & C,D,E,F,H,J,K,L,N,W \\
\hline 15.(WL) & C,I,L,P,S,T,V,X & B,C,D,E,G,I,J,K,L,M,N,O,P,Q,S,T,V,X \\
\hline 16.(AL) & I,L,M,P,S,T,V, & I,J,K,L,M,P,Q,S,T,V \\
\hline 17.(GWR) & M,P,S,T,X & I,K,M,O,P,Q,S,T,X \\
\hline 18.(BI) & I.M & B,C,D,E,F,I,J,K,G,L,M,N,P,Q,R, T,X \\
\hline 19.(PG) & D,E,F,P,S & C,D,E,F,H,J,L,M,P,S, \\
\hline & & \\
\hline
\end{tabular}




\begin{tabular}{|l|l|}
\hline GI benefits & A-X \\
\hline GI assets & $1-19$ \\
\hline
\end{tabular}

\begin{tabular}{|c|c|c|c|c|c|c|c|c|c|c|c|c|c|c|c|c|c|c|c|}
\hline$\frac{(1-19)}{(A-X)}$ & $\begin{array}{c}1 \\
-(\mathrm{PS})\end{array}$ & $\begin{array}{l}2 \\
\text { (CS) }\end{array}$ & $\begin{array}{l}3 \\
\text { (ST) }\end{array}$ & $\begin{array}{l}4 \\
\text { (IES) }\end{array}$ & $\begin{array}{l}5 \\
\text { (DL) }\end{array}$ & $\begin{array}{l}6 \\
\text { (CSC) }\end{array}$ & $\begin{array}{l}7 \\
\text { (RGS) }\end{array}$ & $\begin{array}{l}8 \\
\text { (AGS) }\end{array}$ & $\begin{array}{l}9 \\
\text { (UF) }\end{array}$ & $\begin{array}{l}10 \\
\text { (GS) }\end{array}$ & $\begin{array}{l}11 \\
\text { (GB) }\end{array}$ & $\begin{array}{l}12 \\
\text { (GR) }\end{array}$ & $\begin{array}{l}13 \\
\text { (cWL) }\end{array}$ & $\begin{array}{l}14 \\
\text { (GW) }\end{array}$ & $\begin{array}{l}15 \\
\text { (wL) }\end{array}$ & $\begin{array}{l}16 \\
\text { (AL) }\end{array}$ & $\begin{array}{l}17 \\
\text { (GWR) }\end{array}$ & $\begin{array}{l}18 \\
\text { (BI) }\end{array}$ & $\begin{array}{l}19 \\
\text { (PG) }\end{array}$ \\
\hline A. & L & L & L & L & L & L & M & M & L & L & L & VL & L & VL & L & L & L & L & L \\
\hline To & & & & & & & & & & & & & & & & & & & \\
\hline$x$ & L & L & L & VL & L & VL & L & L & M & L & L & VL & L & L & $\mathrm{M}$ & M & $\mathrm{H}$ & L & L \\
\hline
\end{tabular}

Figure 5: Sample to illustrate the method used for the expert's opinion table. The assets listed in Section 4.2.1 from 1-19 evaluated by the benefits listed in Section 4.1 from $\mathrm{A}-\mathrm{X}$.

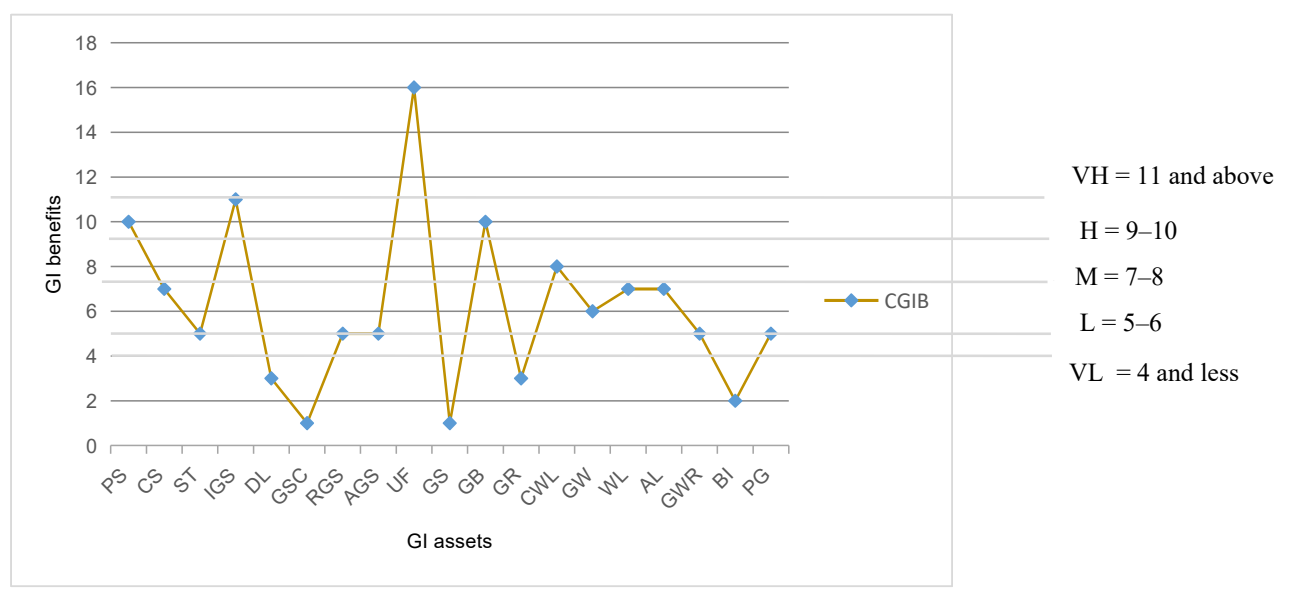

Figure 6: Category of multifunctionality.

GI value percentage difference is the calculated percentage difference, between each asset possible GI benefits (PGIB) and each asset current GI benefits(CGIB), that they are giving. The result, through relative percentage differences calculator, indicates the lower the current GI assets benefits are, the higher the difference is and vise verse. In the case of the 19 assets, six assets have the value difference below 50\%, which are closer to the possible estimated benefits they could give. Still, the remaining 13 assets value difference is greater than or equal to $50 \%$, which made the GI value difference gap high. Both categories of multifunctionality and the GI value difference results indicate. The need for green infrastructure strategies soon. The result in Fig. 7 shows the difference between the possible GI asset benefits and the current benefit that they are giving, indicating which GI assets could or should be restored or improved.

Green infrastructure delivers an adverse range of benefits - environmental, economic, and social benefits to urban dwellers. While the term GI has been around for a long time, but it is still essential to promote GI benefits. A more accurate view of green infrastructure assets and their benefits help local governments, professional and community decide where, 

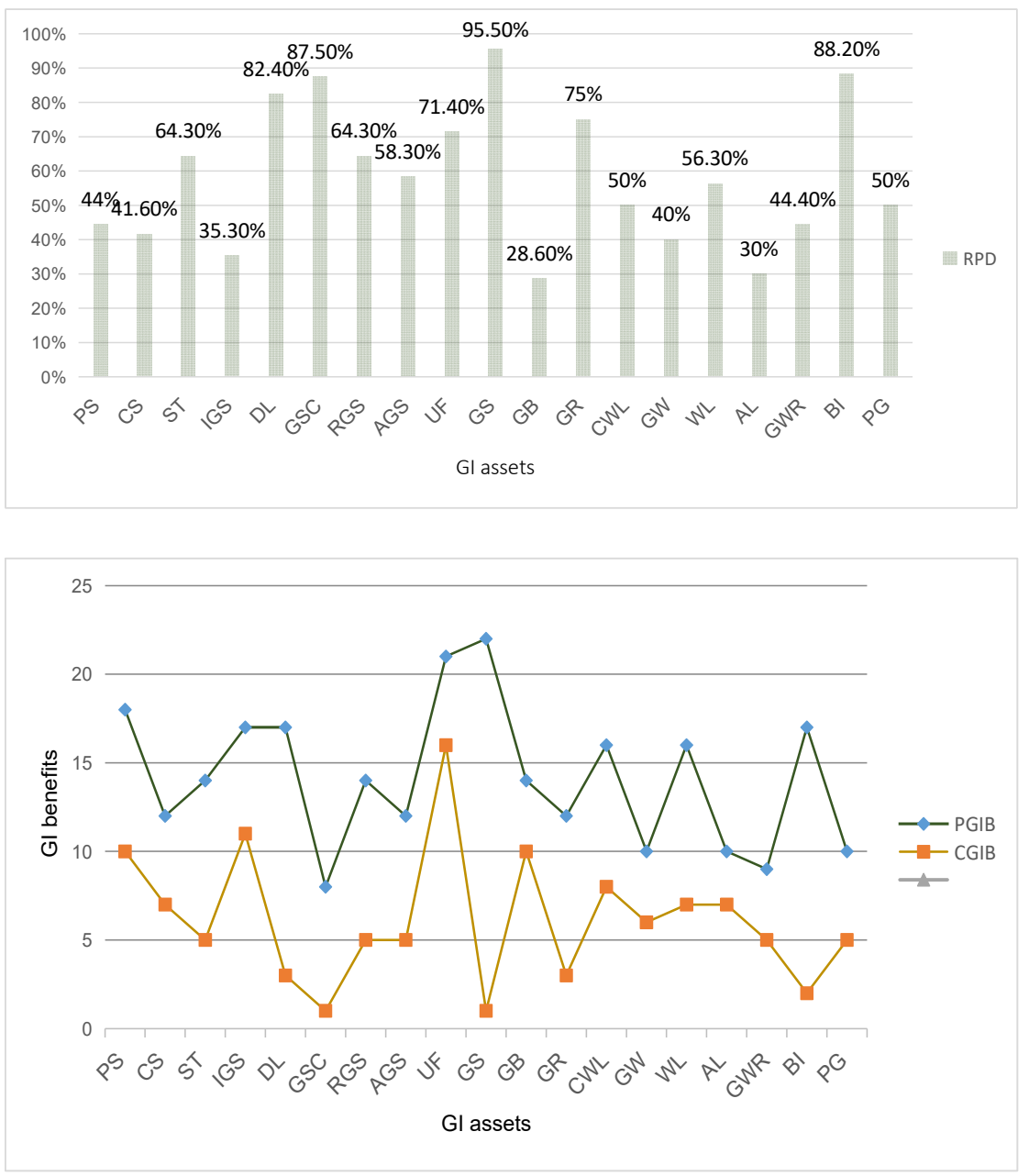

Figure 7: GI value difference.

when, and to what extent green infrastructure practices should become part of future planning. Addis Ababa needs to stress and work on the strategies introduced. The existing assets need to be further evaluated and planned to enable the potential benefits they can give (Fig. 6).

Some limitations of this study should be acknowledged. First, the data contained in the case reports were limited. The identified current benefits of Addis Ababa's selected GI assets were based on the advantages described by experts for each of the 19 GI assets. Thus, some bias on the part of the experts should be considered, which may have affected which benefits were identified. Although this study tried to diminish this type of bias by using site investigation and numerous studies, this approach does not represent a statistically significant method.

Despite the limitations, this study has an indication of multiple benefits of green infrastructure in holistically connected systems. The estimated value differences and 
category of multifunctionality can show direction for further research and identify which GI asset need the attention soonest. Furthermore, this study can be used as a checklist for the new ongoing projects in the city.

\section{ACKNOWLEDGEMENTS}

This study is the result of the work of experts from institutions and international organizations, who are Lecturers, researchers, and practicing professionals. And we would like to express our special thanks of gratitude. Here is a list of names involved in one way or another from people who helped us to collect data, site investigation, and experts involved in the evaluation. Abel Estifanos (planner and stormwater expert); Ahmed Mukhtar(urban designer); Amehaselassie Damtew (data collector); Beniam Geberu (urban planner and heritage expert); Bezawerk Geremew (architect and urban planner); Bezawit Getachew (urban economist); Brook Tesfamichael (environmental and chemical engineer); Eden Teklemariam (landscape and environmental planner); Eskinder Gedelu (architect and planner); Haftom Asmelash (architect and urban planner); Negede Tesfaye (land management); Wubengeda Tsegaye (landscape and environmental planner); Zebad Alemayehu (urban planner and environmental planner). This report would not have been possible without all these people's involvement.

\section{REFERENCES}

[1] Naumann, S., Mckenna, D., Kaphengst, T., Pieterse, M., Rayment, M., Design, implementation and cost elements of green infrastructure projects. Final report to the European Commission. Ecologic Institute and GHK Consulting: Overland Park, KS, USA, 2011.

[2] Benedict, M. \& McMahon, E., Green infrastructure linking landscapes and communities. Island Press: Washington, DC, 2006.

[3] Little, C.E., Greenways for America, The Johns Hopkins University Press: Baltimore and London, 1990.

[4] Norton, B.A., Coutts, A.M., Livesley, S.J., Harris, R.J., Hunter, A.M. \& Williams, N.S.G., Planning for cooler cities: A framework to prioritise green infrastructure to mitigate high temperatures in urban landscapes. Landscape and Urban Planning, 134, pp. 127-138, 2014.

[5] Setala, H., Viipola, V., Rantalainen, A.-L., Pennanen, A. \& Yli-Pelkonene, V., Does urban vegetation mitigate air pollution in northern conditions? Environmental Pollution, 183, pp. 104-112, 2013.

[6] Ulrich, R.S., Simons, R.F., Losito, B.D., Fiorito, E., Miles, M.A. \& Zelson, M., Stress recovery during exposure to natural and urban environments. Journal of Environmental Psychology, 11, pp. 231-248, 1991.

[7] Nordh, H., Hartig, T., Hagerhall, C.M. \& Fry, G., Components of small urban parks that predict the possibility for restoration. Urban Forestry and Urban Greening, 8, pp. 225-235, 2009.

[8] Forest Research, Benefits of green infrastructure. Report by Forest Research, Defra research contract number WC0807, Farnham, 2010.

[9] Landscape Institute, Green infrastructure: An integrated approach to land use. Landscape Institute Position Statement. 2013. www.landscapeinstitute.org/policy/green-infrastructure/. Accessed on: 8 Sep. 2019.

[10] Addis Ababa City Plan Commission Office, 2019.

[11] Jalayer, F. et al., Climate change induced risk analysis of Addis Ababa city (Ethiopia). Vol. 15, EGU2013-9457, 2013. 
[12] ITDP, www.itdp.org/wp-content/uploads/2020/01/In-Ethiopia-New-Leadership.

[13] Paget, S. \& Regan, H., Ethiopia plants more than 350 million trees in 12 hours. https://edition.cnn.com/2019/07/29/africa/ethiopia-plants-350-million-trees-intl-hnk/ index.html. Accessed on: 3 Feb. 2020.

[14] City of Bradford Metropolitan District Council, Bradford city center GI study, 2014. www.bradford.gov.uk/Documents/CityCentreActionPlan/Publication/draft/ Evidencebase/Greeninfrastructurestudy.

[15] Elliott, R. et al., Identifying linkages between urban green infrastructure and ecosystem services using an expert opinion methodology. Ambio, 49, 2019. DOI: 10.1007/s13280-019-01223-9.

[16] Burley, B.A., Green infrastructure and violence: Do new street trees mitigate violent crime? Health and Place, 54, pp. 43-49, 2018.

[17] Rasidia, M.H., Jamirsahb, N. \& Saidc, I., Urban green space design affects urban residents' social interaction. Cairo ASIA Pacific International Conference on Environment-Behaviour Studies, 31 Oct.-2 Nov., Cairo, Egypt, 2012.

[18] Tzoulas, K. et al., Promoting ecosystem and human health in urban areas using green infrastructure: A literature review. Landscape and Urban Planning, 81, pp. 167-178. DOI: 10.1016/j.landurbplan.2007.02.001.

[19] Marusic, B.G., Social behaviour as a basis for design and development of green infrastructure, pp. 130-149, 2015. DOI: urbani-izziv/10.5379.

[20] Lennon, M., Douglas, O. \& Scott, M., Urban green space for health and well-being: Developing an "affordances" framework for planning and design. Journal of Urban Design, 2017. DOI: 10.1080/13574809.2017.1336058.

[21] Mekala, G.D., Jones, R.N. \& MacDonald, D.H., Valuing the benefits of creek rehabilitation: Building a business case for public investments in urban green infrastructure. Environmental Management, 2015. DOI 10.1007/s00267-015-0471-7.

[22] Valánszki, I., Dancsokné Fóris, E. \& Filepné Kovács, K., Parallel development of green infrastructure and sustainable tourism: Case studies from Hungary. Polish Journal of Natural Science, 33, pp. 625-647, 2018.

[23] Mcpherson, G., Simpson, J.R., Peper, P.J., Maco, S.E. \& Xiao, Q., Municipal forest benefits and costs in five cities. Journal of Forestry, pp. 411-416, 2005.

[24] Krause, B., Culmsee, H., Wesche, K., Bergmeler, E. \& Leuschner, C., Habitat loss of floodplain meadows in north Germany since the 1950s. Biodiversity and Conservation, 20, pp. 2347-2364, 2011.

[25] Dixon, K.K. \& Wolf, K.L., Benefits and risks of urban roadside landscape: Finding a Livable, balanced response. Proceedings of the 3rd Urban Street Symposium, 24-27 Jun. 2007, Seattle, WA, Transportation Research Board of the National Academies of Science: Washington DC, 2007.

[26] Gill, S., Handley, J.F., Ennos, R. \& Pauleit, S., Adapting cities for climate change: The role of the green infrastructure. Built Environment, 33, pp. 115-133, 2007. DOI: 10.2148/benv.33.1.115.

[27] Cotner, L. et al., The effectiveness of green infrastructure at improving water quality: A literature review, 2010.

[28] Cole, L., McPhearson, T., Herzog, C. \& Russ, A., Green infrastructure. Urban Environmental Education Review, eds A. Russ \& M.E. Krasny, Cornell University, 2017.

[29] Carter, J., The potential of urban forestry in developing countries: A concept paper. FAO: Rome, 1995. 
368 Sustainable Development and Planning XI

[30] Singh, V.S., Pandey, D.N. \& Chaudhry, P., Urban forests and open green spaces: Lessons for Jaipur, Rajasthan, and India. RSPCB Occasional Paper No. 1. Rajasthan State Pollution Control Board 4-Jhalana Institutional Area, Jaipur 302017, Rajasthan, India, 2010.

[31] Dzhambov, A. \& Dimitrova, D., Green spaces and environmental noise perception. Urban Forestry and Urban Greening, 14, pp. 1000-1008, 2015.

DOI: 10.1016/j.ufug.2015.09.006. 